\title{
IHC 65. Análisis de los argumentos para decidir su autenticidad o falsificación y nuevas aportaciones científicas*
}

\section{IHC 65. Analysis of the reasons for deciding its authenticity or falsification and new scientific contributions}

\author{
Concepción Fernández Martínez \\ Universidad de Sevilla
}

\section{RESUMEN}

El trabajo presenta un doble análisis cuyas conclusiones aportan argumentos para fijar la datación de la inscripción de Honorato conservada en Sevilla. En primer lugar un análisis comparativo del texto de la inscripción con el de un nuevo manuscrito de la RAH; y en segundo lugar un análisis científico del soporte (superficie e incisión de las letras), con software y equipo de microscopía adecuados, extendido a diversas piezas de características y cronología similares.

\section{SUMMARY}

The paper presents a double analysis whose conclusions provide arguments to set the dating of the inscription dedicated to Honoratus preserved in Seville. Firstly, a comparative analysis of the text of the inscription with that of a new manuscript of the RAH, and secondly, a scientific analysis of the surface and incision of the letters, with specific software and and appropriate microscopy equipment, extended to different inscriptions of similar characteristics and chronology.

PALABRAS CLAVES: Latín, Epigrafía.

KEY WORDS: Latin, Epigraphy.

Mientras trabajábamos en la redacción del CIL XVIII/2, dedicado por entero a los CLE de Hispania ${ }^{1}$, hace poco más de una década, tuvimos la ocasión de ocuparnos con detalle del Carmen dedicado al obispo Honorato (Fernández Martínez y Carande

\footnotetext{
* El trabajo se desarrolla en el marco del Proyecto I+D+i Inscripciones latinas en verso de Hispania. Tratamientos multimedia para la investigación y su transferencia (ref. FFI200910484). La autora es Investigadora Responsable del Grupo de Investigación del PAIDI (ref. HUM156).

${ }^{1}$ El volumen está ya en fase avanzada de edición. Asimismo, los resultados del proyecto se han hecho públicos en un portal web bilingüe español-inglés, con tres bases de datos interconectadas: www.clehispaniae.com.
}

Herrero 2002: 13-30; Fernández Martínez et alii 2007: 318-327), conservado entonces en la Catedral de Sevilla y trasladado recientemente a la Iglesia de El Salvador, de la misma ciudad. Un trabajo previo de Gimeno y Miró (Gimeno y Miró 1999: 241-257) trataba de demostrar que esta pieza epigráfica no era una realización antigua, sino una falsificación grabada muchos siglos después de la vida y muerte de Honorato (589-641), esgrimiendo para ello argumentos variados, como las singulares características del soporte y su insólita decoración, ciertos detalles curiosos o exagerados relacionados con la paleografía, los nexos, el sangrado o la compaginación, y algunas otras "rarezas" relacionadas más bien con el texto, que fueron analizadas, contestadas y contraargumentadas en el citado trabajo de 2002 que realizamos conjuntamente Carande y yo misma. Las conclusiones de aquel trabajo, lejos de deshacer las incertidumbres relacionadas con el hallazgo de la inscripción, y sin llegar a resolver su carácter original o reciente, ofrecía argumentos, basados en paralelos conocidos y relacionados con el soporte, la ordinatio, la paleografía y el texto, que nos parecieron suficientes como para no restar autenticidad al Carmen de Honorato.

Diez años después, y fruto de un Seminario Internacional organizado por la $\mathrm{UAB}^{2}$, una de las autoras del referido trabajo de 1999, H. Gimeno, vuelve sobre el controvertido epitafio de Honorato. Su trabajo de 2012 (Gimeno 2012: 83-98) se basa sobre todo en la aparición de una versión manuscrita del texto que, en opinión de la autora, confirma sus viejas sospechas

\footnotetext{
${ }^{2}$ International Seminar, Stones, parchments and papers. The memory of Roman epigraphy from Late Antiquity to Baroque, Universidad Autónoma de Barcelona, 13-15 diciembre de 2011.
} 
sobre la falta de antigüedad de la inscripción del arzobispo. La presunta datación del epígrafe en el siglo VII queda también descartada, siempre en opinión de la autora, en virtud de la observación del soporte con un "microscopio electrónico", cuyos resultados se expusieron en el mismo Seminario y se publican en el mismo volumen (Sánchez Velasco 2012: 55-69). Pero vayamos por partes.

Sin prejuicios sobre su autenticidad o falsificación (aunque aún se pueden aportar algunas pruebas científicas), sin que medien intereses ni en un sentido ni en el otro, diez años después de mi trabajo conjunto con Carande, me sigue pareciendo mucho más difícil demostrar la falsificación del epígrafe que argumentar su autenticidad. Y corroborando esta dificultad, precisamente, el trabajo de Gimeno 2012 concluye, en su último párrafo, que todo lo dicho en las páginas precedentes "no es más que una hipótesis indemostrable" (Gimeno 2012: 96). Difícilmente, pues, a partir de una hipótesis indemostrable podría extraerse una conclusión tan tajante como la certeza de que el epitafio de Honorato no se hubiese grabado en el siglo VII (Gimeno 2012: 83), haciéndolo desaparecer, en consecuencia, de los distintos repertorios, colecciones o antologías de inscripciones latinas antiguas.

Procede, pues, encontrar argumentos - yo no diría pruebas - que puedan resultar demostrables, objetivos y, sobre todo, esclarecedores.

Si la reafirmación de la falsificación de la pieza procede fundamentalmente del descubrimiento de un nuevo manuscrito de la $\mathrm{RAH}^{3}$, y de su análisis comparativo con el texto grabado en el soporte de mármol, corresponde valorar este análisis ${ }^{4}$ con cierto detenimiento, centrándonos sobre todo en los aspectos que puedan resultar más significativos.

\section{EL MANUSCRITO DE PORRAS DE LA CÁMARA}

El manuscrito está incluido en un códice titulado Inscripciones recogidas en Sevilla por Porras de la Cámara y contiene papeles varios de los siglos XVI y XVII. Según nos transmite Gimeno, algunos de los papeles del códice podrían haber pertenecido a Luciano de Negrón (Sevilla 1541-1606), a quien va dirigida la scheda con la inscripción de Honorato ${ }^{5}$.

Si observamos la imagen que nos proporciona Gimeno (Gimeno 2012: 87) y la comparamos con la inscripción conservada, vemos que el manuscrito no

\footnotetext{
${ }^{3}$ Ms. de Porras de la Cámara, fol. 213

${ }^{4}$ Sin entrar ahora en el análisis de los demás manuscritos o transcripciones, lo que ya se hizo en el citado trabajo de 2002.

${ }^{5}$ Para más detalles sobre la posible datación del manuscrito, cf. Gimeno 2012: 84.
}

reproduce el soporte (el texto aparece simplemente dentro de un recuadro), cambia bastante la ordinatio (no respeta los sangrados de las líneas pares, ni ajusta el texto contra el borde derecho del soporte), no coincide en todos los nexos, e ignora la primera línea (que en la piedra solo se lee a medias y con dificultad, pues el soporte que se conserva está roto por su parte superior). Diferencias todas que conviene valorar en su justo medio (Figs. 1 y 2).

En opinión de Gimeno (Gimeno 2012: 95) el nuevo manuscrito no reproduce el texto grabado en el soporte y el análisis de sus diferencias la lleva a concluir que este texto manuscrito no es una transcripción de la inscripción antigua que hoy conservamos en su soporte, sino una invención renacentista para garantizar la primacía de la sede hispalense sobre la toledana.

"Si tuviéramos que creernos el dibujo, la inscripción no estaba rota y habría estado grabada en una placa, el soporte habitual para las inscripciones funerarias de dignidades eclesiásticas en Hispania en el siglo viI" (Gimeno 2012: 88).

Sin embargo, si atendemos el modo en que los humanistas suelen transcribir los textos epigráficos (que dicen haber visto y tenido entre sus manos, en muchas ocasiones), no tenemos por qué 'creernos el dibujo'. Martín Camacho (Martín Camacho 2012: 195-205) ${ }^{6}$ nos muestra evidencias de la "escasa atención que, por lo general, la mayoría de los autores anteriores al XIX han prestado a los aspectos materiales de las inscripciones", centrándose en el texto y descuidando el soporte en toda su dimensión; es decir, su aspecto formal y material, la ordinatio, y hasta detalles no menores como las interpunciones, los nexos, y la medida y proporción de las letras. Ya mucho antes Mayer (Mayer 1984: 35-57), nos advirtió de la absoluta falta de interés de los humanistas por este tipo de datos materiales, formales o paleográficos. El trabajo de Martín Camacho está ilustrado con ejemplos de manuscritos que no dibujan ningún soporte, aunque nos conste en algunos casos que sus autores lo tuvieron a la vista. Y todavía son mucho más explícitos en este sentido los casos, no excepcionales, en que para una misma inscripción distintos autores han dibujado distintos soportes. ¿Qué conclusión podemos sacar, por ejemplo, del soporte del carmen de Castro del Río que Pérez Bayer y Villacevallos ‘dibujaron' respectivamente como muestran las siguientes imágenes? (Martín Camacho 2012: 203) (Figs. 3 y 4). ${ }^{7}$

\footnotetext{
${ }^{6}$ Martín Camacho ha publicado en 2010 un volumen fruto de su tesis doctoral (título y referencia) y más recientemente, fruto del mencionado Seminario Internacional, un interesante trabajo titulado "Dibujando poemas. Acerca de la transcripción de los CLE al papel".

${ }^{7}$ Imágenes gentilmente cedidas por Martín Camacho.
} 


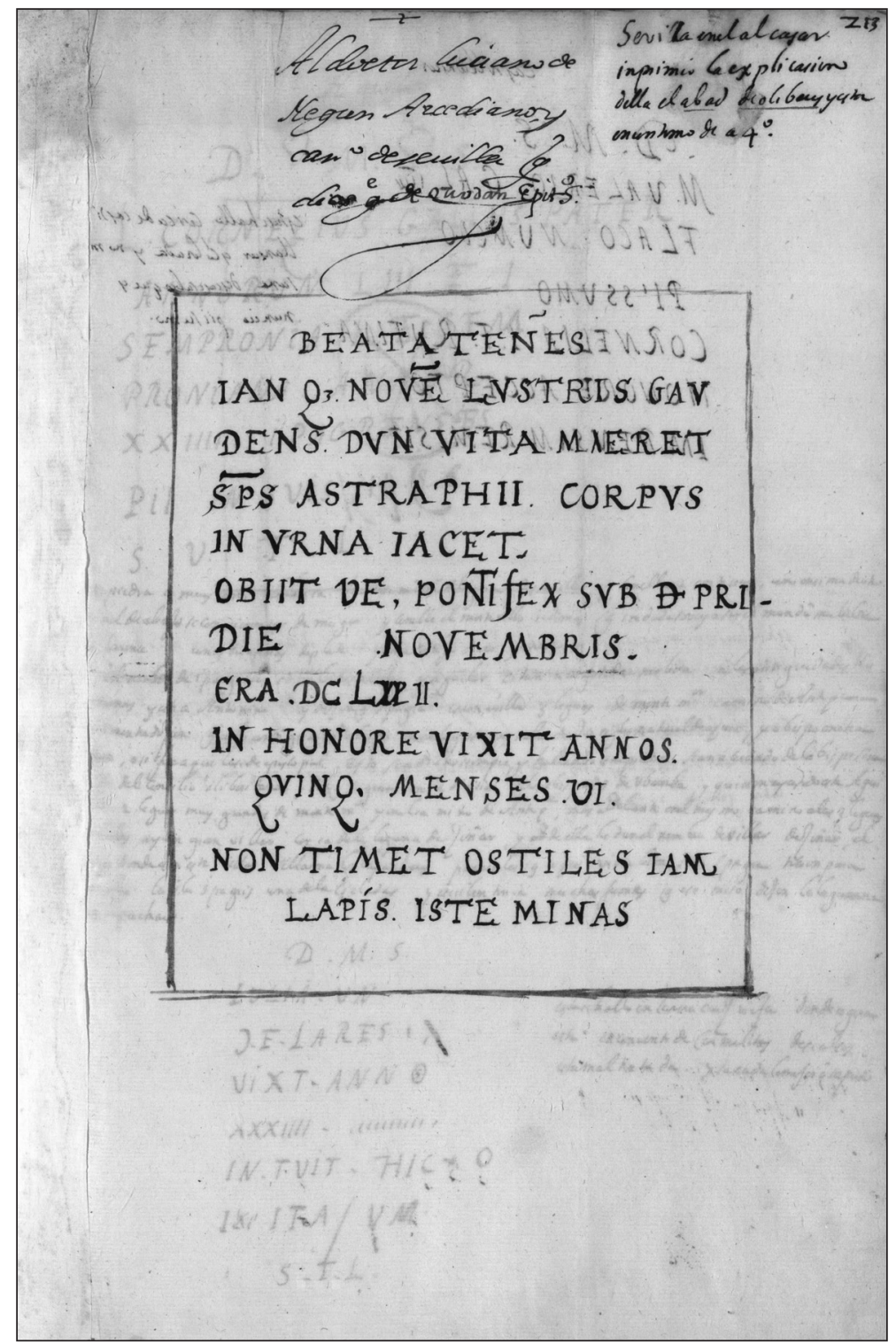

Figura 1. Ms. de Porras de la Cámara, fol. 213.

El hecho, pues, de que el manuscrito en cuestión no dibuje el soporte de IHC 65 no impide, en absoluto, que el autor del manuscrito copiara la inscripción directamente del soporte.

Pero las diferencias no afectan solo al dibujo o no de su soporte, sino que se extienden a diversos aspectos relacionados con la ordinatio y con la propia lectura del texto, que repasaremos a continuación, siempre con el objetivo de poder aclarar, a través del análisis, que no es demostrable ni está demostrado que IHC 65 se grabara a partir del manuscrito de Porras de la Cámara (no antes del siglo XVII, por tanto), y que no es imposible que tal manuscrito se escribiera tomando como modelo la inscripción grabada sobre su soporte.

IHC 65 resulta aparentemente legible hoy por hoy, pero esto es más una apreciación de conjunto que una realidad en sus detalles. Algunos de sus rasgos o características paleográficas pueden hacer difícil su lectura; difícil hoy, con la pieza perfectamente limpia y bien conservada, y no sabemos si mucho más difícil hace siglos (en 1606), cuando no podemos llegar a saber su estado de conservación ni su grado de limpieza. 


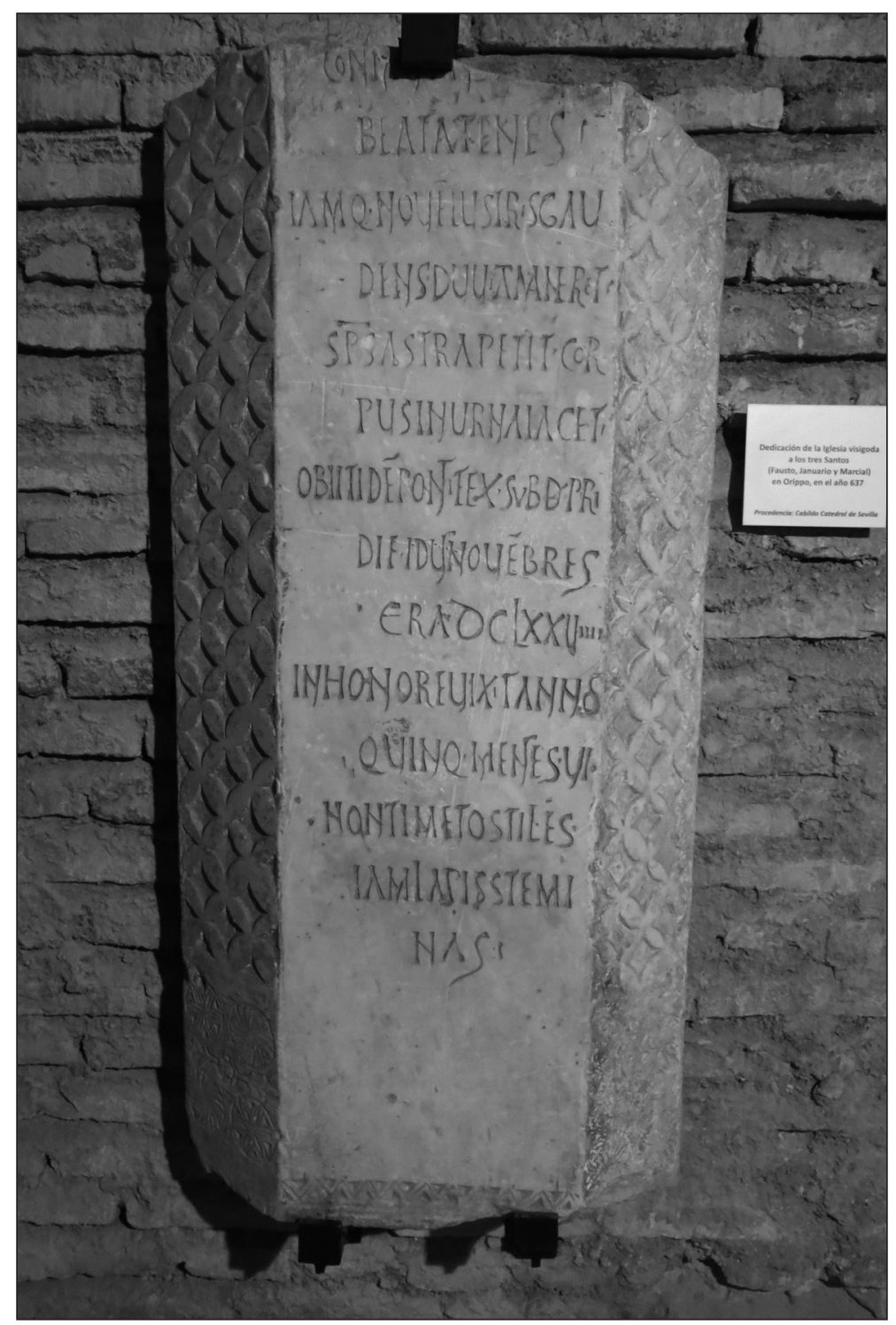

Figura 2. IHC 65. Foto de J. Beltrán, en su ubicación actual.

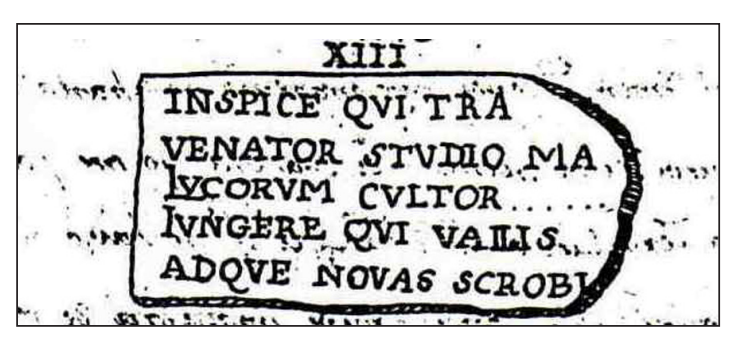

Figura 3. Ms. de Pérez Bayer.

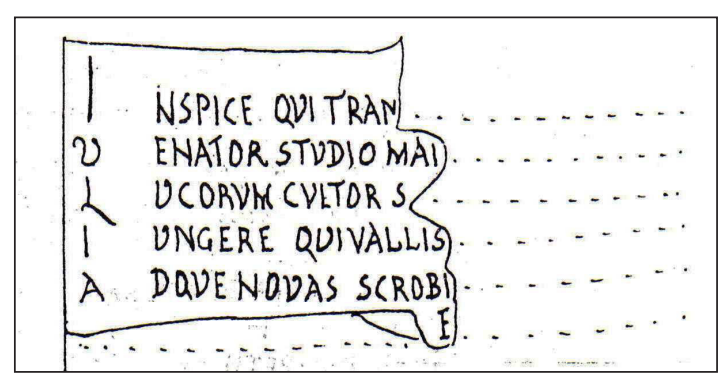

Figura 4. Ms. de Villacevallos. 
Un punto de dificultad para su buena interpretación (y también para su transcripción manuscrita) -aparte del estado de conservación y limpieza que pudiera tener en 1606- lo constituye la abundancia de nexos o la similitud entre las letras E, I y T (como veremos con detalle a continuación). Veamos los pormenores de la transcripción y su comparación con el texto grabado sobre el mármol:

- Es verdad que el manuscrito no transcribe la primera línea, comenzando directamente con beata tenes; pero no es de extrañar que si la piedra estaba sucia en 1606, su transcriptor pudo no haber entendido esas letras que están a medias (conmuṇi șe) - apenas 3 o 4 de ellas se leen bien (cf. figura 5) - y empezar directamente en línea 2, obviando esa línea fragmentaria y las dificultades para restituirla.

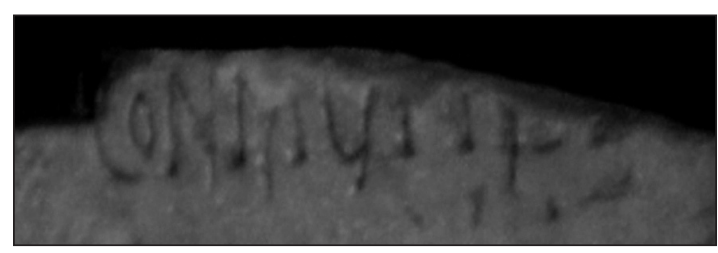

Figura 5. Detalle de IHC 65.

- Las diferencias de la líneas 3 y 4 que afectan a la $\mathrm{n} / \mathrm{m}$ final de iam y dum resultan irrelevantes, pues desde antiguo se conoce la neutralización, en posición final, de ambas consonantes.

- En línea 4 el texto grabado sobre la piedra nos deja leer una forma verbal $m^{\wedge} a n^{\wedge} e r e t$, con dos nexos (cf. Figuras 6A y 6B) que el transcriptor pudo no haber entendido bien, de forma que, interpretando a duras penas las letras amalgamadas del original, escribió MAERET, con una A muy estrecha y sin travesaño, que no se parece a ninguna otra del manuscrito, y que parece confirmar la falta de comprensión del transcriptor.

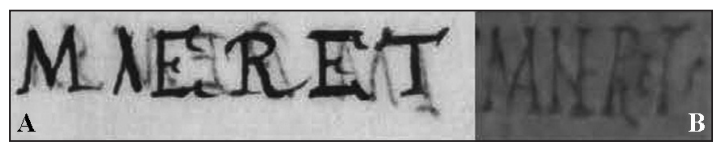

Figuras 6a y 6b. Detalles del manuscrito y de IHC 65.

- La divergencia de la línea 5 resulta definitiva y confirma, en mi opinión, que el manuscrito se hizo a partir del texto grabado en la piedra (y no a la inversa), con algunas lagunas y falta de comprensión por parte del autor. En este caso, el copista no entendió la palabra PETIT en la piedra (por esa similitud entre E, I y T que mencionábamos supra) y escribió PHII (que no es ninguna palabra latina, pero que se parece bastante a lo que se lee a simple vista en el mármol; cf. figuras 7A y 7B.

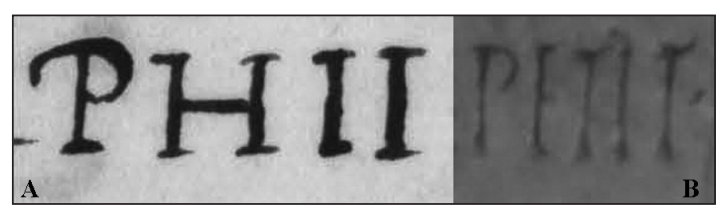

Figuras 7a y 7b. Detalles del manuscrito y de IHC 65.

- Igualmente, en línea 7 el copista no entendió en la piedra esa abreviatura neumática $\operatorname{IDE}(\mathrm{m})$, cuya I está demasiado cerca de la palabra anterior (cf. figuras $8 \mathrm{~A}$ y $8 \mathrm{~B}$ ) y la sustituyó por algo que no sabemos muy bien qué es (Gimeno 2012 interpreta VE. como abreviatura de uenerabilis), pero que en todo caso parece fruto de la incomprensión del original por parte del copista.

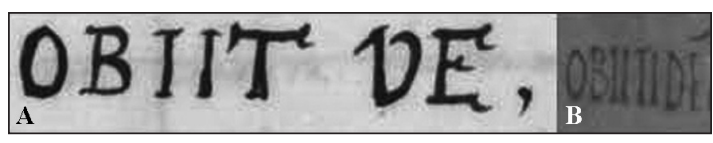

Figuras 8a y 8b. Detalles del manuscrito y de IHC 65 .

- Significativa también es la divergencia de la línea 9, en la que no coinciden los números de la era, lo cual es bastante explicable y resulta tan definitivo para confirmar que el texto manuscrito se copia del grabado en el soporte - y no viceversa- como el caso de la línea 5. El manuscrito transmite DCLXXII, mientras que en el soporte leemos DCLXXVIIII; pero esta cifra del soporte presenta algunas particularidades paleográficas reseñables (cf. figuras 9A y 9B): la V está escrita de forma que podría parecer un II (emborronada por abajo) y las cuatro unidades (IIII) tienen un tamaño mínimo (poco más de $1 \mathrm{~cm}$, mientras que las demás miden entre 3 y $5 \mathrm{~cm}$ ). Tales cifras podrían incluso no verse (dependiendo de las condiciones de conservación y limpieza del soporte), dado que además estaban pegadas contra el borde del campo epigráfico y casi desbordándolo. La lectura que hizo el copista —DCLXXII— es, pues, perfectamente comprensible y fruto de una mala transcripción del texto original. No es el primer ni el único caso en que algunos editores de textos epigráficos obvien en sus ediciones caracteres grabados sobre la piedra en tamaño muy menor ${ }^{8}$. No me parece, pues, que esta

${ }^{8}$ Cf., a modo de ejemplo, González Fernández 1982: 242243 , n. 464 , en la que se edita solo el praescriptum en prosa, 
diferencia relativa a la fecha resulte tan sorprendente como para llevarnos a pensar directamente que el manuscrito en cuestión sea una invención renacentista (Gimeno 2012: 95).

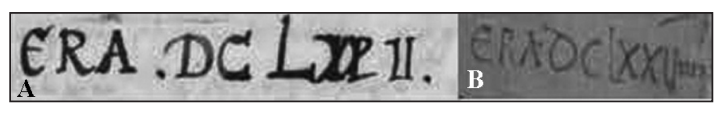

Figuras 9a y 9b. Detalles del manuscrito y de IHC 65.

Otra cosa es ya el epitafio que Tajón dedicó a su hermano Honorato, que no se conserva en piedra y que tiene algunas diferencias muy considerables respecto de IHC 65 y del manuscrito de Porras de la Cámara: sobre todo, las dos líneas iniciales en las que se menciona explícitamente que Honorato sucedió a Isidoro; y una alusión reiterada (y poco explicable si no fuese políticamente interesada) a su escaso don de lenguas... cosas ambas que nos pueden hacer pensar que este epitafio sí pudo ser una invención posterior, con la intención de eliminar a Theodisclo como sucesor de Isidoro ${ }^{9}$, como nos explica Gimeno 2012.

\section{LA RELACIÓN ENTRE EL SOPORTE Y EL TEXTO GRABADO EN ÉL}

La datación del epígrafe en el siglo viI queda también descartada, de nuevo según Gimeno, en virtud de la observación del soporte con un "microscopio electrónico” por parte de Sánchez Velasco, cuyos resultados se expusieron en el mencionado Seminario y se publican en el mismo volumen ${ }^{10}$.

El trabajo en cuestión, bajo el muy ambicioso título Pruebas arqueológicas de la falsedad de la inscripción IHC 65, obvia explícitamente las apreciaciones epigráficas, filológicas y lingüísticas, sin llegar a analizar ni valorar los argumentos de tal naturaleza que en su día expusimos Carande y yo misma en el trabajo ya citado, y centrándose en cuestiones más bien arqueológicas (contexto, soporte y características físicas).

Lamentablemente, el muy complejo contexto arqueológico del carmen de Honorato, y las pocas y contradictorias noticias sobre su hallazgo — como sucede con tantas otras piezas - son de escasa ayuda a la hora de decidir sobre su datación originaria o

obviando el carmen, grabado en tamaño mucho menor $(6 \mathrm{~cm}$ el praescriptum, $0,5 \mathrm{~cm}$ el carmen); cf. la pieza completa en Fernández et alii 2007: 248-249, CA6.

${ }^{9}$ Cf. todos los detalles en Gimeno 2012: 90-92.

${ }^{10}$ cf. supra, n. 7. reciente, pero no pueden llevarnos automáticamente a la conclusión de que la pieza sea falsa.

El soporte, que - también como en muchas otras ocasiones- ha sido, en efecto, reutilizado ${ }^{11}$, ha sufrido un intenso trabajo de pulimento, no solo para suprimir parte de sus decorados sino también para la natural preparación del campo epigráfico antes de su incisión. En esta labor de pulido hace especial hincapié Sánchez Velasco, a quien llama la atención que el campo epigráfico esté libre de impurezas y concreciones, y no tanto los laterales que conservan los motivos decorativos. Sin embargo, como ya observamos en su momento (Fernández Martínez y Carande Herrero 2002) y como corrobora el análisis científico que ofrecemos en estas mismas páginas, parece razonable que se hayan intensificado las labores de pulido en el campo epigráfico — que siempre se prepara para su incisión-, descuidándose los laterales, no ya solo porque no vayan a formar parte del campo epigráfico, sino porque, en este caso concreto, la decoración llena de relieves no admite un cómodo pulido, facilitando además el acúmulo de restos a lo largo de los siglos.

Sánchez Velasco ha usado, según él mismo indica, "un microscopio electrónico USB" para la observación de la pieza, y ha visto huellas de uso de herramientas presumiblemente de hierro con las que habría sido aserrada la pieza epidérmicamente ${ }^{12}$. De esa observación microscópica deduce el autor que la inscripción se habría grabado con una técnica muy "grosera", que incluía el "rascado" del interior de las letras para aumentar su profundidad; de todo lo cual concluye que la inscripción y el soporte pertenecen a épocas muy distintas; y que, procediendo el soporte de una época coetánea a la de Honorato, fue grabada, sin embargo, mucho después (su análisis no le permite precisar cuánto después).

Pero proceden algunas reflexiones al respecto; en primer lugar, en relación con el instrumental utilizado para el análisis, pues no se describen las características del microscopio utilizado, ni el alcance de sus aumentos $^{13}$, por lo que no se pueden valorar objetivamente sus resultados. Y en segundo lugar, porque

\footnotetext{
${ }^{11}$ Por ello, no procede en este caso el análisis de la forma y decoración, para determinar la fecha de ejecución (en todo caso anterior al período de Honorato, como afirma el propio Sánchez Velasco), ni resulta relevante el análisis del material para la identificación del mármol.

12 Conviene recordar que esta técnica de aserrado con instrumentos de hierro se documenta también en época romana y tardoantigua (cf. a este respecto el reciente y clarificador trabajo de Klaus Grewe (Grewe 2010: 381-401).

${ }^{13}$ La única descripción se reduce a nombrar en la página 63 un "microscopio digital USB" ( sic), sin ofrecer ninguna información sobre sus características.
} 
los resultados del análisis deben ser valorados no de manera absoluta sino relativa, es decir, extendiendo el análisis a otras piezas de similares características (datación, soporte, material, tipo de letra, datación, etc.). Sin embargo, en el curso del mencionado análisis, la pieza en cuestión solo se ha comparado con otra $^{14}$, también dedicada a Honorato, de mármol blanco, muy pulido, muy bien compaginada y totalmente distinta en su ejecución; por lo que los resultados, como era previsible, son muy distintos, y no resultan suficientes para reforzar los argumentos o asegurar las conclusiones.

De ahí la doble necesidad de, por un lado, hacer un análisis material, válido desde el punto de vista científico, de la piedra y sus incisiones, con equipo y software especializados para la correcta toma de muestras; y ampliar, por otra parte, el análisis a otras piezas de la misma época y similares características de incisión y ejecución. Solo así podríamos extraer conclusiones metodológicamente aceptables en torno a la datación, temprana o reciente, de la inscripción de Honorato.

Para ello, hemos contado con el equipo especializado, material y humano, del Servicio de Microscopía (S.M.) de la Universidad de Sevilla (http://investigacion.us.es/scisi/sgi/servicios/microscopia), un Servicio General de Investigación (http://investigacion.us.es/ scisi/sgi) destinado a facilitar la infraestructura y apoyo técnico para que se lleven a cabo trabajos de investigación que requieran el uso de variadas técnicas de microscopía. La investigación desarrollada en el S. M. abarca una gama amplia y heterogénea de temas, implicando a muy diversas áreas de conocimiento. El S. M. cuenta con los equipos necesarios para la observación de muestras materiales, en microscopía electrónica de transmisión y barrido, microscopía óptica y de fuerzas atómicas.

Para la correcta observación microscópica de IHC 65, un equipo formado por los doctores Patricia Aparicio (subdirectora del CITIUS), Francisco Varela y Consuelo Cerrillos (especialistas en Microscopía), José Beltrán (arqueólogo) y yo misma ${ }^{15}$, nos desplazamos a la Iglesia de El Salvador, donde se ubica en la actualidad la pieza. Hemos utilizado una Lupa

${ }^{14}$ Se trata de IHC 363, también dedicada a Honorato y conservada hoy igualmente en la Iglesia de El Salvador de Sevilla. Cf. para más detalles Fernández et alii 2007: 312317, SE5.

${ }^{15}$ Agradezco a todos ellos su entusiasmo, entrega y profesionalidad, durante los días que duró el trabajo de campo y los que sucedieron hasta la elaboración y entrega del informe. Es de justicia reconocer la ayuda y asesoría de J. Beltrán en relación con los soportes, materiales, incisión, decoración, datación, etc., así como agradecer las fotografías tomadas por él mismo y cedidas para su uso en este trabajo.
Leica S8APO, dotada de cámara Leica DC300 (figura 10). Se ha trabajado con el software Leica IM50, versión 1.20, para la visualización de las imágenes, obteniéndose los siguientes resultados (en cada imagen se muestra la escala a la que está hecha la foto; junto con las imágenes de la lupa se han realizado fotografías con cámara Nikon de alta resolución para localizar a escala real las zonas estudiadas sobre las distintas piezas). La tabla siguiente (Fig. 11) muestra los detalles fotográficos de distintas zonas estudiadas sobre la inscripción de Honorato y resultado de la observación con lupa.

Como puede apreciarse en las imágenes, el campo epigráfico muestra huellas claras de los trabajos de pulido necesarios y habituales para la preparación del mismo en cualquier soporte (reutilizado o no); que las herramientas para llevar a cabo tales tareas de pulido fuesen o no de hierro no nos confirma o desmiente nada en relación con el carácter más o menos reciente de la incisión. Asimismo, y como era de esperar, los laterales con decoración dejan ver huellas claras de las incrustaciones y depósitos de distintos materiales a lo largo de los siglos.

En cuanto a las letras, el equipo de microscopía utilizado nos muestra de modo evidente una incisión profunda y firme en toda la inscripción; de lo cual ofrecemos en la figura 11 algunas muestras: la I de pontifex, en 1. 7; la $\mathrm{S}$ de menses en 1. 11, de la que se muestran distintas imágenes ampliadas, tanto de su remate como de su trazo; y la $\mathrm{N}$ de gaudens, en 1. 4 , de la que se muestran sus dos remates, superior e inferior, y el ángulo de encuentro entre los dos trazos.

Para tener datos de referencia con los que poder comparar los resultados de este análisis y extraer conclusiones plausibles, nos hemos desplazado al Museo Arqueológico de Sevilla, donde se han observado, con los mismos equipos de microscopía, las siguientes piezas ${ }^{16}$ :

- Un soporte de mármol blanco sin inscripción, casi idéntico al del carmen de Honorato, hallado en Dos Hermanas y que Sánchez Velasco describe como la cubierta de tumba ${ }^{17}$ (Figura 12); el soporte presenta unas características muy similares al que nos ocupa (un bloque octogonal y con la misma decoración de cuadrifolias en ambas caras laterales, que debió de pertenecer al mismo taller de producción, y formaba parte de un conjunto de restos arqueológicos hallados al sur de la antigua ciudad de Orippo (Dos Hermanas, Sevilla), fechado por Escacena en virtud de sus motivos y técnicas decorativas a fines del siglo VI o durante el VII, fechas que coinciden con las de la

\footnotetext{
16 Todas en la sala 26 del MAS.

${ }^{17}$ IHC 363.
} 


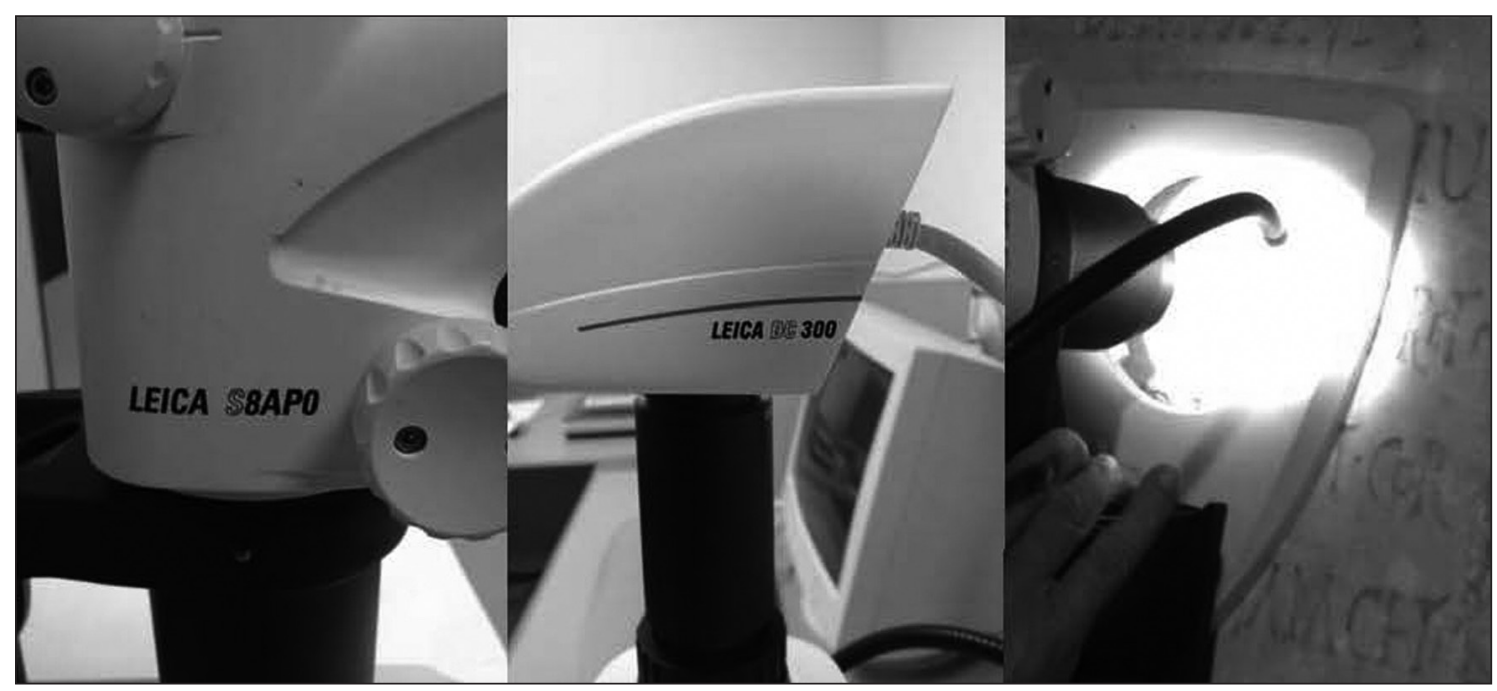

Figura 10. Lupa Leica S8APO, cámara Leica DC300 y detalle de la toma de muestras en la Iglesia de El Salvador.

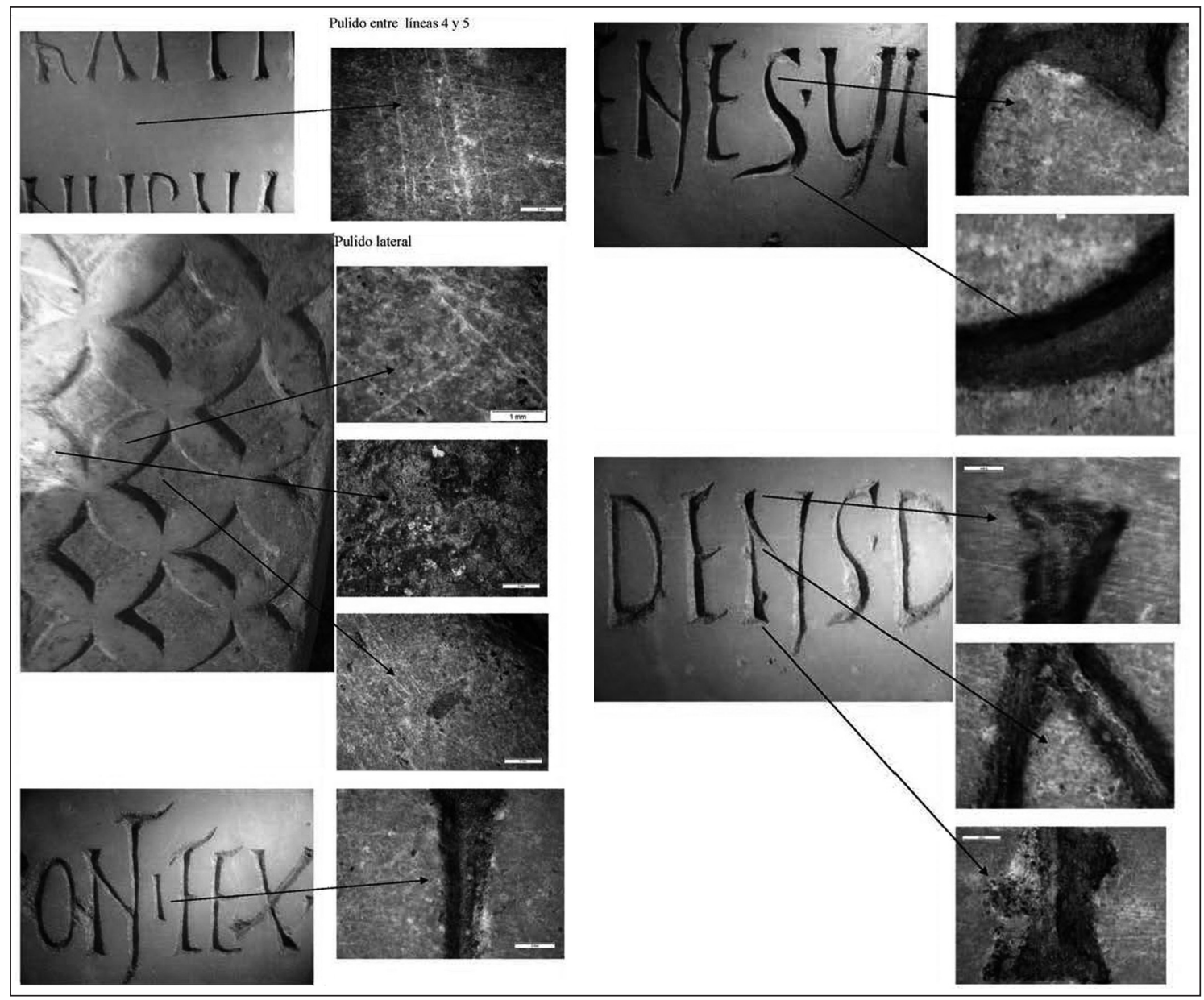

Figura 11. Detalles fotográficos de distintas zonas estudiadas sobre la inscripción de Honorato y resultado de la observación con la lupa. 


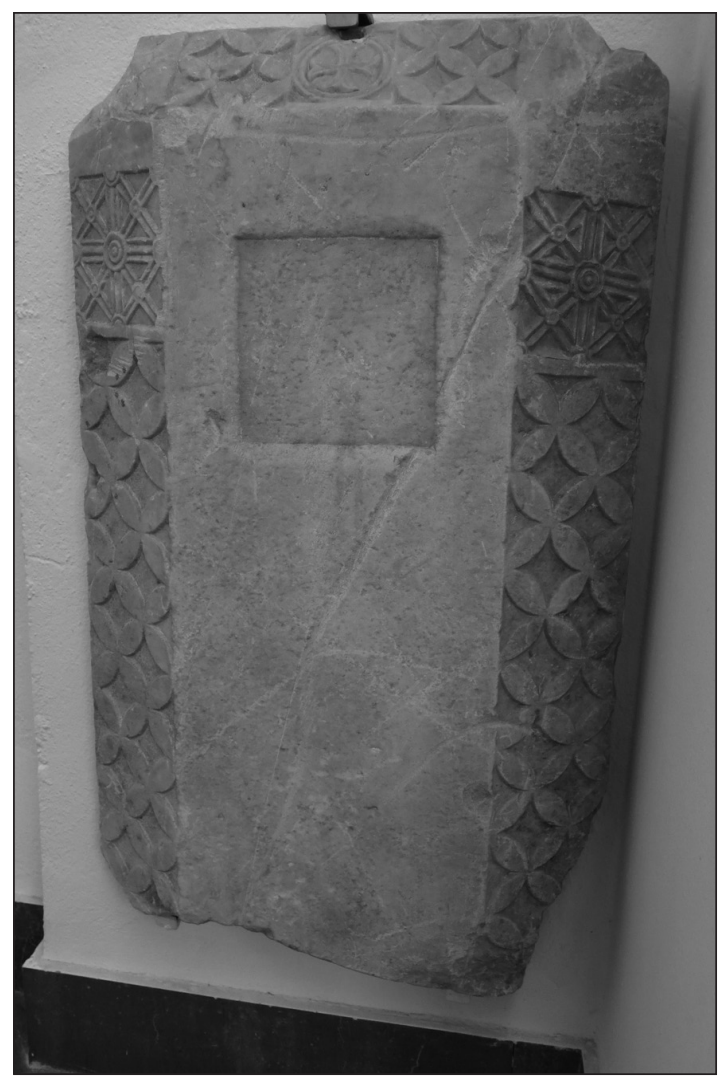

Figura 12. Cubierta de tumba. Foto de J. Beltrán.

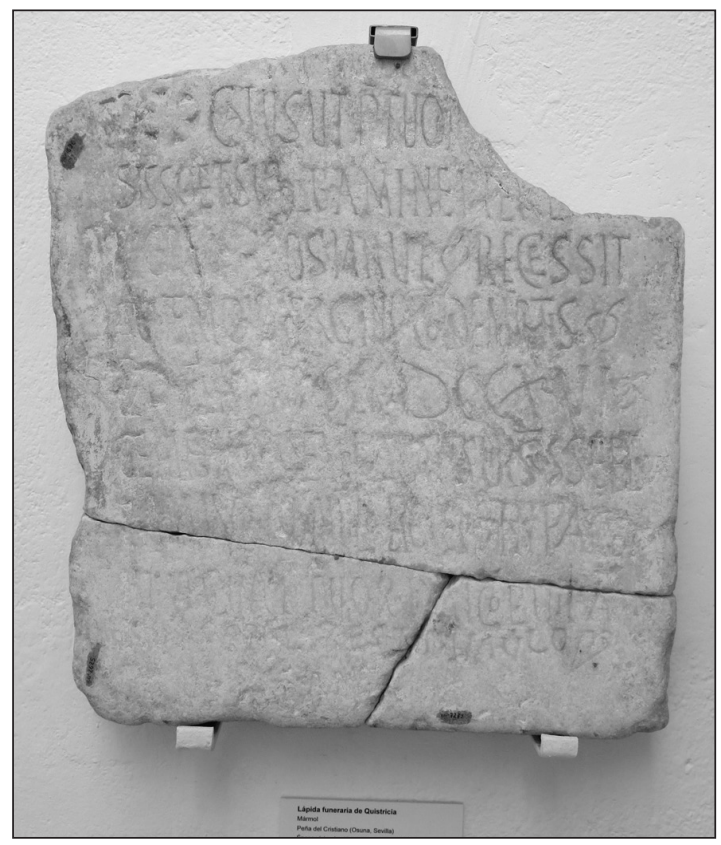

Figura 14. Placa de Quistricia. Foto de J. Beltrán.

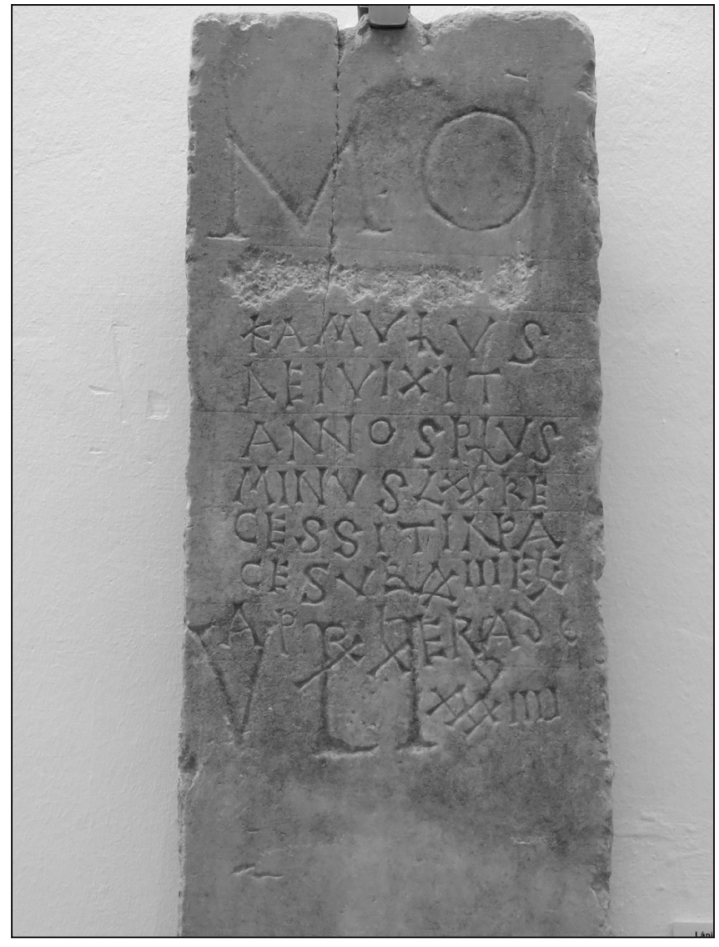

Figura 13. Placa de Leoncio. Foto de J. Beltrán

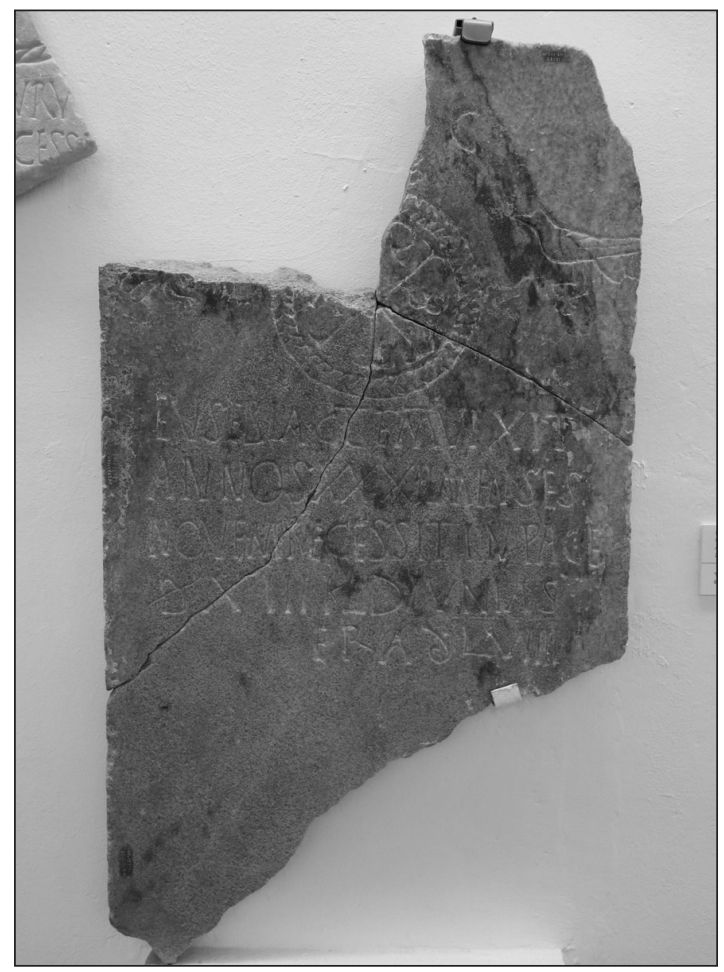

Figura 15. Placa de Eusebia. Foto de J. Beltrán. 


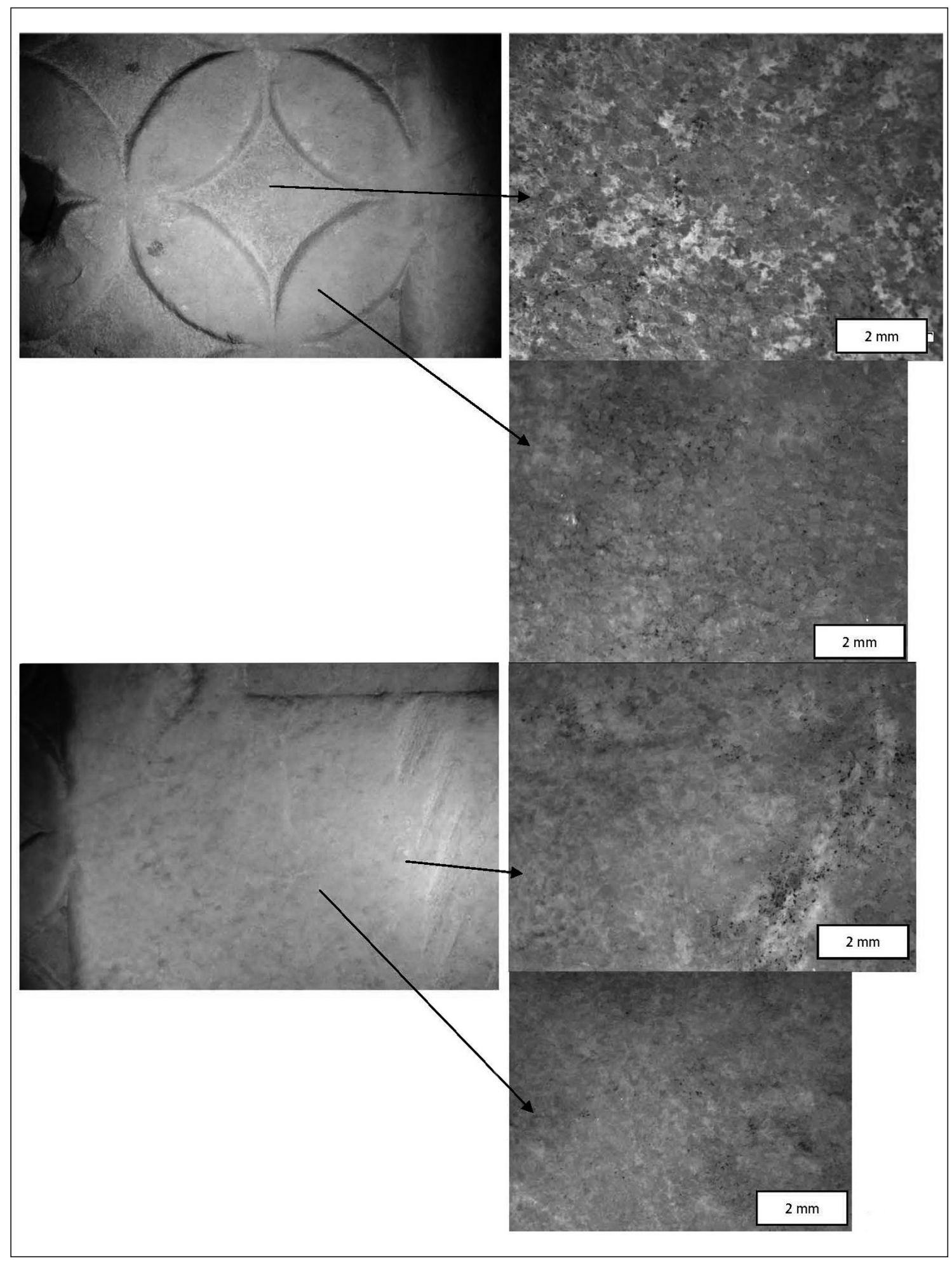

Figura 16. Zonas estudiadas en la cubierta de tumba procedente de Dos Hermanas. 


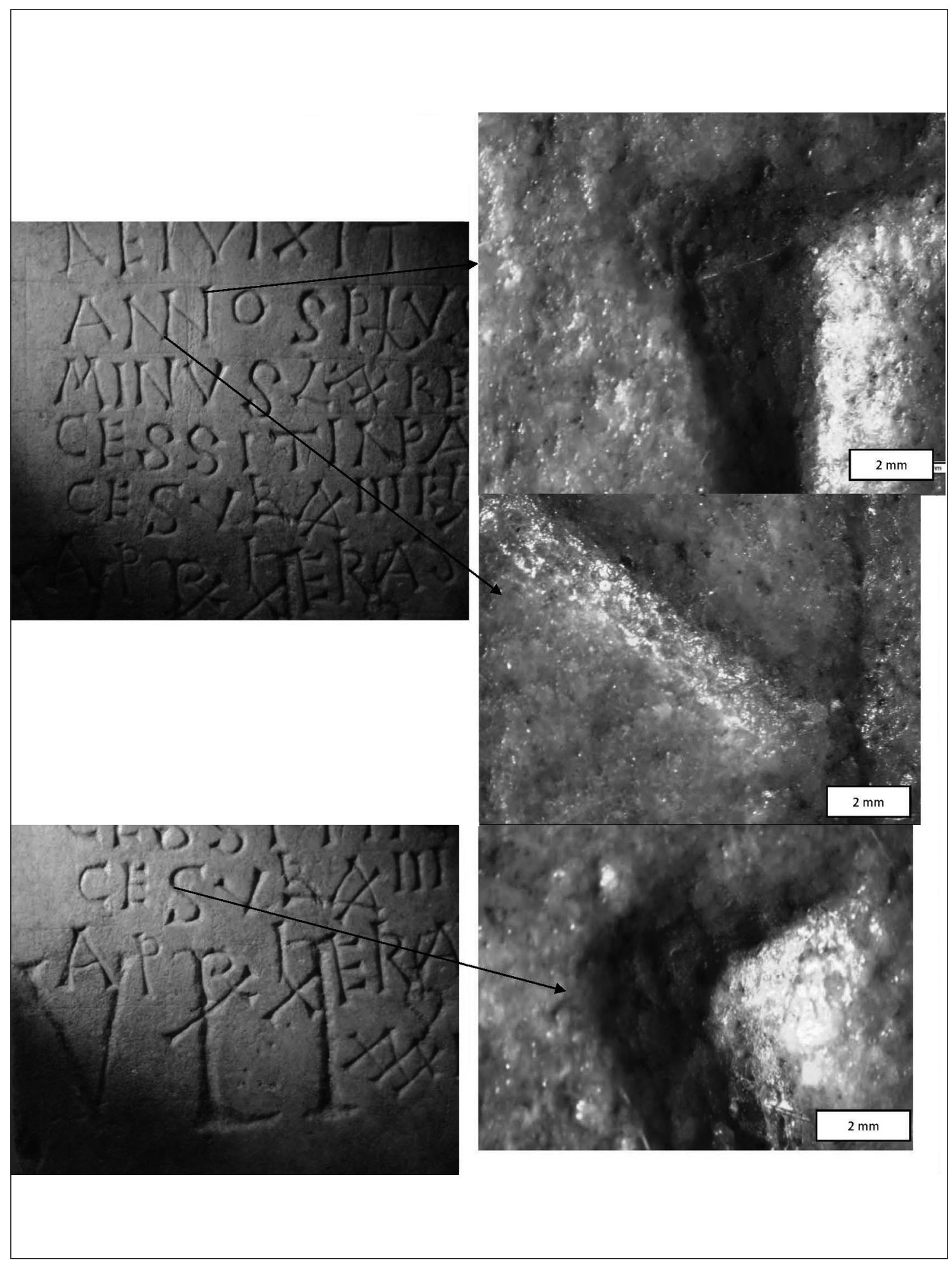

Figura 17. Zonas estudiadas en la placa funeraria de Leoncio. 




Figura 18. Zonas estudiadas en la placa funeraria de Quistricia. 


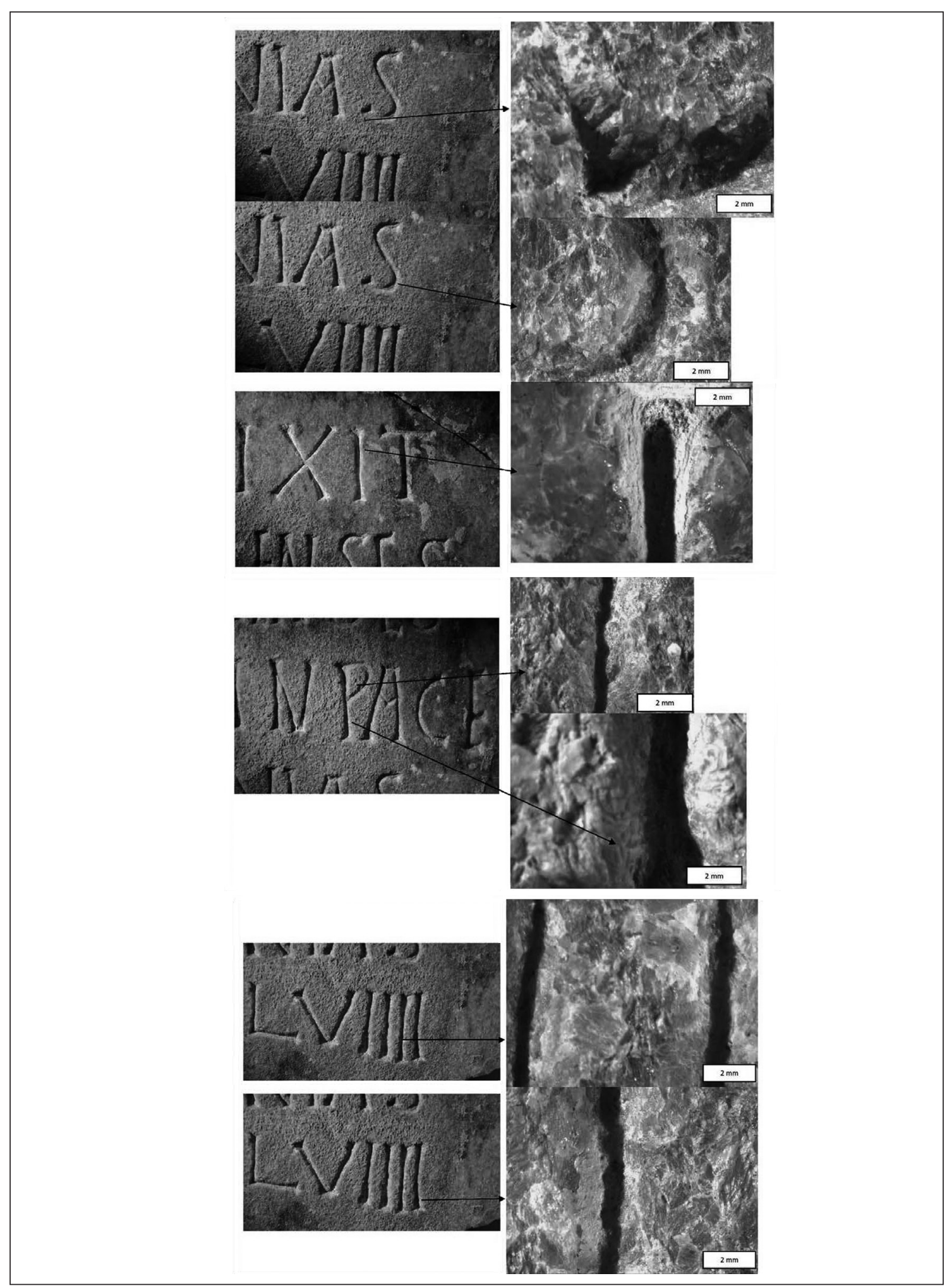

Figura 19. Zonas estudiadas en la placa funeraria de Eusebia. 
redacción del Carmen de Honorato (Escacena 198586: 321-331, esp. 322) $)^{18}$.

- La placa funeraria de Leoncio, procedente de Écija, grabada en el año 596 (mármol blanco) sobre una inscripción anterior ${ }^{19}$ (Figura 13).

- La placa funeraria de Quistricia, procedente de Osuna y grabada en el año $708^{20}$ (mármol blanco de Almadén de la Plata), (Figura 14).

- Y la placa funeraria de mármol gris dedicada a Eusebia, procedente de Aznalcázar, grabada en el año $501^{21}$ (Figura 15).

En las respectivas tablas se muestran los detalles fotográficos de las distintas zonas estudiadas en estas piezas y el resultado de la observación con la lupa descrita Cf. figuras 16 a 19.

Los resultados del análisis aplicado a todas las piezas, con equipo y software especializados para la correcta toma de muestras, hablan por sí solos, ayudándonos a ver cómo la observación microscópica de los detalles del pulido del campo epigráfico, de los motivos decorativos y de la incisión de las letras nos muestra unos resultados muy similares en todos los casos, ya se trate de letras de gran tamaño o de pequeño tamaño, de sus astas, de sus ángulos o de sus remates. Los trazos de las letras de la pieza de Honorato se asemejan a los de estas otras inscripciones de fechas más o menos coetáneas y de la misma área geográfica, conservadas en el MAS. Así pues, y como muestran las tablas, la inscripción dedicada a Honorato no presenta signos distintivos respecto de las demás que nos puedan llevar a concluir que el soporte y las letras pertenezcan a épocas muy alejadas, ni a sospechar, por tanto una falsificación intencionada en fecha muy posterior y con unas técnicas muy distintas.

En conclusión, el análisis comparativo del nuevo manuscrito de la $\mathrm{RAH}^{22}$ con el texto grabado en el soporte de mármol y la detenida valoración de sus diferencias no pueden asegurar que el texto manuscrito no sea una transcripción de IHC 65, sino que más bien nos animan a pensar lo contrario, como hemos tratado de demostrar en la primera parte de este trabajo. Y, por último, tales sospechas sobre la falta de antigüedad de la inscripción de Honorato no se ven confirmadas, sino más bien desmentidas, por el análisis con el equipo de microscopía aplicado a

\footnotetext{
${ }^{18}$ Cf. Escacena, J. L., "Un cimacio visigodo procedente de cortijo 'Bastero' (Coria del Río, Sevilla)”, Estudios de Historia y Arqueología Medievales V-VI (1985-86) 321-331, esp. 322.

${ }^{19} \mathrm{CIL} \mathrm{II}^{2} / 5,1281$ = CILA SEVILLA, vol. 4,1247 = HEp-6, $871=$ AE 1995,771b.

${ }^{20} \mathrm{CIL} \mathrm{II}^{2} / 5,1115=$ CILA SEVILLA, vol. 3,671 = IHC 96 (p. 2,54) = IHC $533=$ ICERV 159.

${ }^{21}$ CILA SEVILLA II, 1029 = HEp 2, 1990, 622.

${ }^{22}$ Ms. de Porras de la Cámara, fol. 213.
}

la pieza en cuestión y a otras de características y datación similares ${ }^{23}$.

\section{BIBLIOGRAFÍA}

$\mathrm{AE}=$ Année Épigraphique.

CIL $\mathrm{II}^{2} / 5=$ Corpus Inscriptionum Latinarum. Volumen Secundum. Editio altera. Pars V. Conuentus Astigitanus. Ediderunt A. U. Stylow, R. Atencia Páez, J. González Fernández, C. González Román, M. Pastor Muñoz, P. Rodríguez Oliva; adiuvantibus H. Gimeno Pascual, M. Ruppert, M. G. Schmidt, 1998.

CILA SEVILLA = Corpus de Inscripciones Latinas de Andalucía, vol. II (Tomos I-IV): Sevilla, (J. González Fernández ed.), Sevilla, 1991-1996.

Escacena, J. L. 1985-1986: "Un cimacio visigodo procedente del cortijo 'Bastero' (Coria del Río, Sevilla)", Estudios de Historia y Arqueología Medievales V-VI, 321-331.

Fernández Martínez, C. y Carande Herrero, R. 2002: "Dos poemas epigráficos dedicados a Honorato: Nuevo estudio de IHC 65 y 363", Laboratorio de Arte 15, 13-30.

Fernández Martínez, Carande Herrero, R., del Hoyo Calleja, J., Gómez Pallarès, J., Martínez Gázquez, J., Escolà Tuset, J. M., Martín Camacho, J., Hernández Pérez, R. y Gómez Font, X. 2007: Carmina Latina Epigraphica de la Bética romana. Las primeras piedras de nuestra poesía, Sevilla, 318-327, SE6.

Gimeno, H. y Miró, M. 1999: “Carmina para Honorato, obispo de Hispalis: la polémica inscripción del sucesor de san Isidoro", Archivo Español de Arqueología 72, 241-257.

Gimeno, H. 2012: "Supersunt adhuc lapidis hostiles minae: de nuevo sobre la inscripción de Honorato, pontífice hispalense", Veleia 29, 83-98.

González Fernández, J. 1982: Inscripciones romanas de la provincia de Cádiz, Cádiz.

Grewe, K. 2010: "La máquina romana de serrar piedras. La representación en bajorrelieve de una sierra de piedras de la Antigüedad, en Hierápolis de Frigia y su relevancia para la historia técnica", V Congreso de las Obras Públicas Romanas. Las

${ }^{23}$ Aún nos quedaría una última posibilidad para intentar fijar la antigüedad de la pieza, realizando un análisis de los restos de partículas que pudieran permanecer en el interior de las letras o en sus poros; pues, en el caso de encontrar materia orgánica, se podría proceder a la datación absoluta mediante técnica de carbono 14; y, en el caso de que tales partículas fuesen inorgánicas, también cabría una datación relativa mediante la técnica de termoluminiscencia. 
técnicas y las construcciones de la Ingeniería Romana, Madrid, 381-401.

HEp = Hispania Epigraphica .

ICERV = Vives, J. 1969: Inscripciones Cristianas de la España romana y visigoda, Barcelona.

$I H C=$ Hübner, E. 1871: Inscriptiones Hispaniae Christianae, Berlin.

Martín Camacho, J. 2012: "Dibujando poemas. Acerca de la transcripción de los CLE al papel", Veleia 29, 195-205.
Mayer, M. 1984: “Epigrafia hispánica y transmisión literaria con especial atención a la transmisión manuscrita", R. Etienne (ed.), Epigraphie hispanique. Problemes de methode et d'edition, Paris, 35-57. Sánchez Velasco, J. 2012: "Pruebas arqueológicas de la falsedad de la inscripción IHC 65. La necesaria simbiosis entre epigrafía y arqueología para el conocimiento de la Antigüedad tardía en la Bética", Veleia 29, 55-69.

Recibido: 27-09-2013

Aceptado: 08-01-2014 